Revista de la red interuniversitaria de estudios sobre las literaturas rioplatenses contemporáneas en Francia

17 | 2017

Hermetismo programático en la literatura rioplatense contemporánea (de 1980 a nuestros días)

\title{
Pizarnik y Gelman ante la ley inaccesible
}

\section{Edgardo Dobry}

\section{OpenEdition}

\section{Journals}

Electronic version

URL: http://journals.openedition.org/lirico/3914

DOI: 10.4000/lirico.3914

ISSN: 2262-8339

\section{Publisher}

Réseau interuniversitaire d'étude des littératures contemporaines du Río de la Plata

\section{Electronic reference}

Edgardo Dobry, «Pizarnik y Gelman ante la ley inaccesible », Cuadernos LIRICO [En línea], 17 | 2017,

Puesto en línea el 17 diciembre 2017, consultado el 20 abril 2019. URL : http://

journals.openedition.org/lirico/3914; DOI : 10.4000/lirico.3914

This text was automatically generated on 20 April 2019

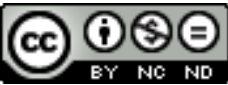

Cuadernos LIRICO está distribuido bajo una Licencia Creative Commons Atribución-NoComercialSinDerivar 4.0 Internacional. 


\title{
Pizarnik y Gelman ante la ley inaccesible
}

\author{
Edgardo Dobry
}

\section{La « rebelión de los hijos»}

1 En L'ange de l'histoire, Stephane Mosès aplica el concepto de « rebelión de los hijos » a la situación en el mundo judío centroeuropeo entre finales del siglo XIX y principios del XX:

La rebelión de los hijos [...] adoptó, en el microcosmos familiar judío, la dimensión de una verdadera inversión de valores. Quizá no sea casual que la invención del complejo de Edipo y su papel fundamental en la creación de la psique date de los primeros años del siglo XX y se haya producido precisamente en Viena, donde el proceso de asimilación de los judíos de Europa Central alcanzaba en aquella época su apogeo (Mosès 1992: 301-302; mi traducción).

2 Ese proceso de asimilación, y los consiguientes problemas de mala consciencia que causaba en el seno de las comunidades judías, se pone de manifiesto especialmente en la «Carta al padre» de Kafka. Allí «son las ambigüedades del padre frente a su propio judaísmo, las inconsecuencias de una pregunta en nombre de la cual el hijo es invitado a permanecer fiel a valores que el padre no ha sido capaz de transmitirle (ni, con mayor motivo, legitimar) priva al discurso paterno de credibilidad » (Mosès 303). Kafka, en la "Carta », dice no comprender por qué su padre, "para quien el judaísmo se reducía a nada », le reprochaba a él « no hacer un esfuerzo mayor en practicar esa misma nada ». Mosès afirma que en Viena, Praga y Berlín « la asimilación social había llevado ya al olvido de la lengua hebrea, al desconocimiento de los textos tradicionales y a la ignorancia total de los significados metafísicos del judaísmo » (304). La religión judía, sus ritos en la sinagoga, la vida comunitaria en torno al calendario del año hebreo, se habían vuelto « un cuadro vacío, desprovisto de sentido » (306). Es la misma situación que indujo a Gershom Sholem a poner en el corazón de la obra de Kafka « la cuestión de la Ley »; es decir, la idea, muy presente sobre todo en $E l$ proceso, de que existe una verdad, pero ya es indescifrable; o, dicho en otros términos, de que la Ley sigue estando ahí pero ya no hay acceso a ella. En la correspondencia entre Scholem y Benjamin, a propósito de la figura 
del estudiante en las ficciones de Kafka, se habla de « escolares sin Escritura » (Scholem) o bien de aquel que " ya no sabe descifrar la Escritura » (Benjamin). En ambos casos está en juego el futuro de la tradición en un mundo definitivamente secularizado. Scholem creía en una especie de plasticidad infinita de la tradición, y en ella basaba su idea de una "teología negativa», un concepto cercano pero a la vez distinto del nihilismo nietzscheano que empezaba a estar en boga por entonces.

3 Esta idea de "escritura indescifrable", ya se trate de texto sagrado o profano, es extraordinariamente fértil, pues permite poner en relación la obra de Kafka con los experimentos de la vanguardia que le fueron contemporáneos y con los que, en apariencia, nada tiene que ver. No tanto con el surrealismo sino, y quizás sobre todo, con Dada y los poemas escritos en lenguas inventadas, como en Hugo Ball y Kurt Shwitters, etapa final del repliegue sobre sí misma y de la opacidad que el simbolismo francés puso en el corazón de lo que Mallarmé denominó « crisis de verso »1. En el caso de Kafka, se trataría de una lengua extremadamente saturada de significado, pero indescifrable por olvidada o nunca suficientemente aprendida; en el caso de los poetas dadaístas, es una lengua asemántica, hecha de sonidos puros, inventada, una música verbal que se rebela contra (en palabras de Hugo Ball) « la lengua que había sido completamente corrompida por el periodismo » (Ball 2005: 139). Se trata, en Kafka, de una lengua muy antigua que ya casi nadie sabe leer, ya casi lengua muerta; en el caso de los experimentos de Dadá, una lengua recién nacida pero destinada a no tener vida, a quedar detenida en su propio alumbramiento, pues nunca ha tenido ni tendrá hablantes. Sin duda hay toda una vía para explorar en esa dirección si se tiene en cuenta que Tristan Tzara, el mismo que, en el primer manifiesto del movimiento, escribió « Dada no significa nada " (Tzara 2004: 13), provenía del meollo de la comunidad judía de Bucarest; su verdadero nombre era Samuel Rosenstock y había nacido en 1896 en el seno de una acomodada familia de comerciantes judíos rumanos. ¿No había anticipado ya otro poeta proveniente del meollo del judaísmo centroeuropeo, vienés en este caso, Hugo von Hoffmansthal bajo la máscara de Lord Chandos (1902), que se le hacía cada vez más difícil escribir en " una lengua de cuyas palabras no conozco ni una sola, una lengua en la que me hablan las cosas mudas y en la que quizás un día, en la tumba, rendiré cuentas ante un juez desconocido (Hofmannsthal 2001: 51)»?

\section{2. ¿Hay « hijos rebeldes » en el Río de la Plata?}

4 La relación entre el idish y el hebreo como lengua viva y lengua muerta iba a invertirse a partir de la creación del Estado de Israel: decretado el hebreo lengua oficial del nuevo país, y arrancado de cuajo de la Europa Central, el idish, por la destrucción completa del mundo judío de esa extensa región, se iba a convertir poco a poco en una lengua sin hablantes. De repente, la lengua sagrada se convertía en idioma nacional; y el idioma que durante siglos había servido de koyné a la nación judía centroeuropea se extinguía en poco tiempo. Las repercusiones de esa tensión en la literatura escrita por autores judíos en América Latina está, quizás, por estudiar. Cosa que nos lleva, además, a formularnos la pregunta: ¿se puede extrapolar el concepto de «rebelión de los hijos» a la primera generación de descendientes de los inmigrantes judíos centroeuropeos en América Latina, en particular en Argentina? Se trataría, en este caso, de un proceso, en parte, similar al descrito por Mosès: el inmigrante judío, precisamente por haber abandonado aquella Europa Central con la consciencia de la imposibilidad del retorno, forma en su nueva 
patria una comunidad para -parafraseando los términos de Scholem- darle un futuro a su tradición. La escuela judía, la sinagoga y los diarios y revistas en idish fueron los instrumentos de esa voluntad. Pero los hijos de esos inmigrantes -sobre todo, los que nacen en la década de 1920 y 1930- plantean una situación hasta cierto punto inesperada: sin renunciar necesariamente a ser judíos, querrán ser argentinos, incorporarse a la vida social, política, cultural del país en el que nacieron y que les ha dado la ciudadanía. No solo una ciudadanía legal, sino también una educación y una perspectiva integradora de futuro. Me propongo estudiar esta tensión en dos poetas pertenecientes a una misma generación, ambos hijos de inmigrantes judíos askenazis: Juan Gelman, nacido en el barrio porteño de Villa Crespo en 1930; y Alejandra Pizarnik, nacida en el suburbio bonaerense de Avellaneda en 1936. Fuera de esas afinidades, la diferencia entre las obras de ambos son tales que casi podríamos hablar de perfecta oposición. En Pizarnik es difícil encontrar una marca del contexto geográfico, político, social en el que escribió. Si podemos hablar de un "hermetismo programático" en su poesía, este consiste, precisamente, en la radical separación de experiencia vivida y experiencia representada en el poema. En este aspecto, Pizarnik es tan antiromántica como lo fueron los simbolistas franceses de la segunda mitad del siglo XIX: Mallarmé, Rimbaud, Lautréamont. Como en ellos, en Pizarnik el poema se separa por completo de todo posible contenido confesional. Su poesía está hecha de paisajes abstractos o fantásticos, de atmósfera simbolista o surrealista. Ni siquiera en su época de París, entre 1960 y 1965, una de las más intensas e importantes de su producción, hay marcas de esa estadía, más allá de algunas dedicatorias a las personas a las que frecuentó, o del prólogo a Árbol de Diana, escrito por Octavio Paz, con quien trabó amistad en París. Salvo en los poemas últimos y póstumos, en particular "Sala de psicopatología », al que luego volveré, Pizarnik parece encontrarse sola en el mundo, en algún paisaje del sueño o de la pesadilla, sin prójimos ni vecinos. Anotación en sus Diarios del 7 de septiembre de 1961: « Noche de insomnio. Pensé con tristeza en el lenguaje. ¿Para qué escribo? Respondí con esta escena imaginaria: vivo en el Tíbet, sola, en una choza. Nunca hablo con nadie pues ignoro el idioma de mis vecinos " (Pizarnik 2003: 268). Gelman, al contrario, es armado poeta, desde el prólogo a su primer libro, Violín y otras cuestiones (1956), por Raúl González Tuñón, poeta orgánico del Partido Comunista Argentino. Desde entonces y, como mínimo, hasta su exilio en 1976, la poesía de Gelman está marcada por el compromiso político y el intento de vincularse a un sustrato popular (Gotán, 1962, apela no solo a la música popular de Buenos Aires sino a su denominación en argot, al vesre), y a un proyecto revolucionario. El registro coloquial se combina con un notorio impulso de invención neológica, que se irá haciendo cada vez más evidente a lo largo de su obra. Ambos son, sin embargo, hijos rebeldes en lo que se refiere al judaísmo. Pero no se trata solo de una divergencia con el origen sino de una tardía, y no del todo lograda (y por eso mismo interesante), vocación de regreso. Tanto en Pizarnik como en Gelman, en efecto, el judaísmo vuelve como inquietud o como apetencia en la obra de madurez, con la convicción de tratarse de algo ya perdido que solo puede evocarse sin alcanzar una plena posesión. También aquí hay, como intentaremos ver, escritura ilegible o Ley presente e inaccesible a la vez.

\section{Revelación del « secreto judío»}

5 El concepto de obra tardía debe utilizarse con precaución en lo que se refiere a una poeta que, como Pizarnik, murió a los treinta y seis años. Es cierto, en todo caso, que la 
presencia explícita del judaísmo -que parece latente a lo largo de toda su obra, en la línea de lo que Tamara Kamenszain llama «el secreto judío» (2007: 76)- solo aparece en sus poemas no recogidos en libro sino póstumamente y en algunas anotaciones en sus Diarios de los últimos años. El « Poema para el padre » está fechado el 23 de noviembre de 1971, apareció en 1972 en la revista caraqueña Árbol de fuego (Pizarnik 2001: 370) y no fue recogido en libro hasta la edición, póstuma, de la Poesía completa:

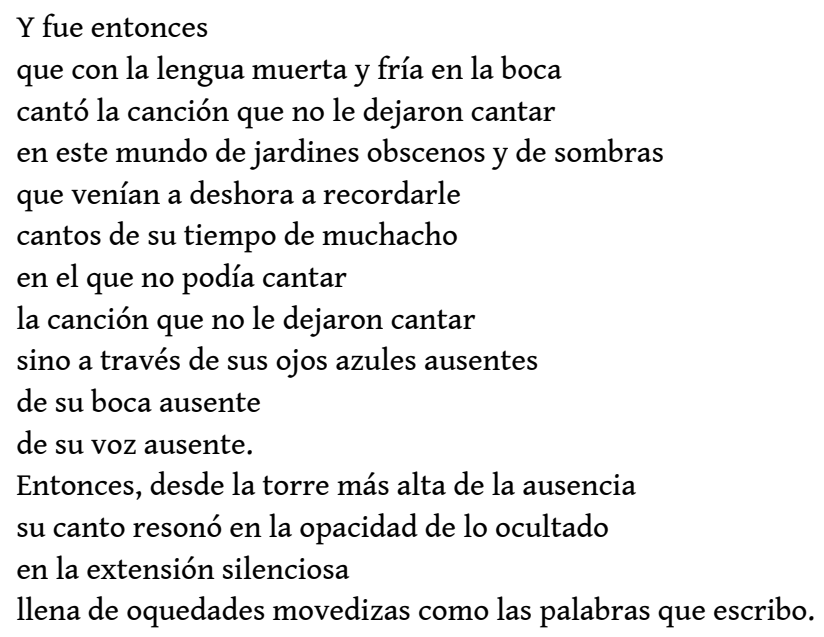

6 El judaísmo, en Pizarnik, aparece ligado a la reivindicación de la figura del padre ya muerto. En el poema, lo ya inaccesible de la tradición aparece junto con la evocación evidente del antisemitismo en la « lengua muerta y fría ». Esta imposibilidad de acceso a la tradición judía, a la que sin embargo pertenece, representa el otro aspecto del programa hermético de Pizarnik: la manera sorda, apenas insinuada, como si fuera a la vez un sobreentendido y algo silenciado, en que aparece -en su poesía- el vínculo con el judaísmo. Esta expresión evoca, por su crudeza y laconismo, el estilo bíblico; por ejemplo, el Salmo 137 (en traducción de Casiodoro de Reina): « Mi lengua se pegue a mi paladar, si de [Jerusalem] no me acordare, si no ensalzare a Jerusalem como preferente asunto de mi alegría ». Es sorprendente la proximidad entre la « lengua muerta y fría » y la lengua que se pega al paladar como condena del judío en la diáspora que olvida su origen y su pertenencia al pueblo de Jerusalem. En el poema de Pizarnik, la canción que «no le dejaron cantar » o que « no podía cantar », la voz está « ausente ». Estos versos retoman una reflexión de los diarios fechada otro 23 de noviembre, cuatro años antes, en 1967; Elías Pozharnik -tal era su verdadero apellido, cambiado a Pizarnik por el funcionario de frontera al bajar del barco que lo traía de Europa; él también podría haber dicho, como Alejandra, que estaba « debajo » de un nombre- había muerto en enero de ese año:

Luego mi cuestión judía, tan nueva. (Ahora es el perrito del piso octavo que debe de haberse asustado de los gritos o de mis maldiciones silenciosas, espero no matarlo por error a uno aunque sus aullidos -agudos, de perrito bebé- están ganando méritos para mon ap. à trépage). (Pizarnik 2003: 430).

7 La frase entre paréntesis puede leerse como un exabrupto persecutorio ante los ruidos de los vecinos, sin relación aparente con la novedad de la cuestión judía. Sin embargo, es significativo que una cuestión tan importante como el judaísmo venga acompañada de una digresión banal sobre los perros y la posible exterminación del animal, aunque sea un bebé. Es cierto que el judaísmo ya había aparecido en los diarios -por ejemplo, el martes 20 de diciembre de 1960: «Al despertar, retornó a mí una canción judía que me apasionaba a los ocho o nueve años » (2003: 178)-, pero solo ahora adquiere desarrollo, va más allá de la mención pasajera y casual. El resto de la entrada de noviembre de 1967, 
como se verá a continuación, confirma lo deliberado -o, como mínimo, lo no casual- de la conjunción entre la cuestión del judaísmo y la molestia del perro. No creo, sin embargo, que se pueda por eso sostener la conclusión que Patricia Venti saca de este pasaje: «En Pizarnik, la alteridad judía/argentina la hizo outsider, un personaje sin un sitio en la sociedad, con pocas posibilidades de disolverse en la masa amorfa y atomizada de una comunidad» (Venti 2008: 166). Pizarnik aborda la novedad de su cuestión judía desde una conciencia fuerte e irrefutable de su nacionalidad argentina, por lo que tal alteridad no es pertinente, ni en ella ni en ningún escritor argentino judío del siglo XX. Es falso, asimismo, que Pizarnik fuera una outsider: su red de relaciones incluía a algunas personalidades relevantes del ambiente literario de su tiempo, como Juan Jacobo Bajarlía, Julio Cortázar, Octavio Paz y, más tarde, a autores jóvenes como César Aira, Ana Becciú, Arturo Carrera. Leer sus diarios como desahogo confesional y tomar al pie de la letra los epítetos que ella misma se adjudica, como « la viajera », « la peregrina », « la emigrante », «la extranjera », no conduce sino a equívocos y malentendidos. Por otra parte, el deseo de « disolverse en la masa amorfa y atomizada de una comunidad» es del todo ajeno a la idea de poeta que toda la obra de Pizarnik proyecta; como, por otra parte, la de la mayoría de poetas de la modernidad.

\section{La cuestión judía como « novedad»}

Persiste, empero, la pregunta: ¿por qué, a sus treinta años, Pizarnik llama «tan nueva » a « mi cuestión judía »? ¿Es una ironía o es que la muerte del padre y el regreso al país después de unos años de ausencia traen consigo una reflexión antes no hecha? Porque, en efecto, todo el resto de la entrada se refiere al padre:

Me siento judía, me siento judía desde que regresé a este país que execro [...] No tolero la estupidez, la incultura de masas de la inteligentzia [...] Je m'en fous de la gentry y heme aquí en pleno soliloquio seudoproustiano (Proust era judío, no es un azar). Siempre me sentí animal (el perrillo del octavo perdura en sus lloros) y de súbito esta molestia de prisionera entre siervos, entre almas muertas. [...] No quiero morir en este país. Padre, padre querido, no quiero morir en este país que -ahora lo sé- odiabas o temías. Del horror que te causaba, de la extranjeridad que te producía, solamente yo puedo dar testimonio [...] nunca podré consolarme y debo irme y morir fuera de este lugar al que no debiste venir, padre, ni yo debí regresar (Pizarnik 2003: 430).

9 Se refiere a su vuelta a Buenos Aires después de los años parisinos, durante los cuales pudo haber evaluado, en algún momento, la opción de quedarse allí permanentemente, como habían hecho otros escritores argentinos, incluido su amigo Julio Cortázar. Pero de eso hacía ya tres años y ahora lo evoca al identificarse con la extranjeridad del padre. «Extranjeridad »: neologismo que parece una suma de extranjería y ajenidad; condición que, atribuida a su padre por antonomasia, representa la figura prototípica del judío errante. Elías Pozharnik había llegado a Argentina a los 26 años y siempre habló el castellano, según parece, con marcado acento. Por otro lado, eso le permite a Pizarnik alejarse de "la incultura de masas" y asociarse a Proust. Es decir, el acercamiento al judaísmo comporta una doble identificación: por lo bajo, con el «perro judío »; por lo alto, con la aristocracia de la inteligencia y la literatura hecha por los judíos europeos. Las referencias al judaísmo son evidentes en el único, y por eso mismo ineludible, poema obsceno que conocemos de Pizarnik, publicado póstumo: "Sala de psicopatología ", escrito en el Hospital Pirovano en 1971. Este poema parece resolver, al fin, la aspiración, 
muy presente en sus diarios, a poseer una fluidez de escritura que Pizarnik identifica con la prosa, cosa que -como analiza Kamenszain en el ya mencionado ensayo- le permitiría llegar a «la novela»: "Quiero escribir una novela pero siento que me falta un instrumento necesario: conocimiento de la lengua » (citado en Kamenszain 2007: 65). Ya que, si bien «Sala de psicopatología » es un poema en verso, el registro de lengua -una combinación de coloquialismo obsceno y paráfrasis de citas cultas- y el carácter narrativo le dan una extensa fluidez, sin comparación dentro de la obra poética de Pizarnik. Es, en efecto, uno de sus pocos poemas que miran hacia afuera, que se acercan al realismo y abandonan la escenografía onírica de raigambre surrealista. Por otra parte, también en este poema el judaísmo aparece ligado a la vez a lo bajo y sucio, y a la alta cultura: « Todo es concha, yo he lamido conchas en varios países y solo sentí orgullo por mi virtuosismo [...] la Reich del lengüetazo, la Reik del abrirse camino entre pelos como de rabinos desaseados -joh el goce de la roña! » (2001: 412). A la vez, también, la identificación con los autores y personalidades prestigiosas: Einstein, Reich, Reik, Freud ( Oh viejo hermoso Sigmund Freud » [415], paráfrasis de la « Oda a Walt Whitman » de El poeta en Nueva York de García Lorca; « Freud, poeta trágico » [416]); y, sobre todo, Kafka:

Pero le pasó (a Kafka) lo que a mí:

se separó

fue demasiado lejos en la soledad

y supo - tuvo que saber-

que de allí no se vuelve

Entonces ya no es Freud el poeta trágico sino la propia Pizarnik: Kafka, en su perspectiva, es un Ulises sin regreso. La idea de «separación » aglutina varios significados: de un lado, la soledad necesaria para la escritura, uno de los asuntos recurrentes en los diarios de Kafka; pero también la imposibilidad de volver a la Ley, a la legibilidad de la tradición, presente, como vimos, en la "Carta al padre ». El hijo rebelde no podría volver a la ortodoxia aunque quisiera, porque ha olvidado la senda de regreso o porque nunca la conoció. Pizarnik anticipa esta lectura en un pasaje del poema del Pirovano (414): « De modo que arrastré mi culo hasta la sala 18,/ en la que finjo creer que mi enfermedad de lejanía, de separación de absoluta NO-ALIANZA con Ellos/ -Ellos son todos y yo soy yo... ». La Alianza, con A mayúscula, es un emblema del pacto entre Dios y los primeros patriarcas de la Torá, por tanto está presente aquí también la separación, es decir el judaísmo como algo todavía presente pero ya inasible: una Alianza que se convierte en No-Alianza.

\section{Gelman y los nombres cambiados}

11 En cuanto a Juan Gelman: hasta el exilio, el judaísmo no aparece como «tema » de su poesía, enfocada a la militancia comunista primero y peronista después. Como en Pizarnik, también hubo cambio de apellido de sus padres al llegar a Argentina, aunque en el caso de Gelman la historia es más compleja. Su padre se llamaba José Mirochnik; el apellido Gelman es una derivación de Hellman, que figuraba en el falso pasaporte alemán que Mirochnik compró para huir de Ucrania. Juan Gelman atribuiría a este apellido doblemente falsificado el origen de su tendencia a utilizar seudónimos y heterónimos: « Traducciones I: Los poemas de John Wendell » (1965-1968); « Los poemas de Dom Pero Gonçalvez »; «Traducciones II: Los poemas de Yamakuchi Ando » (1968); todos estos incluidos en Cólera buey; y Traducciones III: Los poemas de Sidney West (1969). La operación heterónima será central en sus años de exilio europeo, como en Citas y comentarios 
(Madrid, 1982) y Com/posiciones (Barcelona, 1986), en que la voz se enmascara en los poetas medievales judeoespañoles: Ibn Gabirol, Yehuda Halevi, Abraham Abulafia, Isaac Luria; o los místicos del Renacimiento, descendientes de familias judeoconversas, como Teresa de Ávila y San Juan de la Cruz. Además, utilizó heterónimos como José Galván y Julio Grecco.

12 En Pizarnik, como vimos, el judaísmo aparece vinculado a la figura del padre y se vuelve urgente a la muerte de éste; en Gelman es la muerte de la madre la que desencadena un movimiento hasta cierto punto equivalente. Su madre, Paulina Burichson, hija de un rabino de Odessa, había padecido -según la « Carta a mi madre »- los ataques antisemitas de principios de siglo. En ese extenso poema de la última etapa de su obra, «Carta a mi madre (Ginebra, 1984/ París, 1987) », precipitado por la noticia de la muerte de Paulina, Gelman escribe: «Odessa, 1915, tenés 18 años, estudiás medicina, no hay de comer/ [...] esas manzanas ¿tenían rojos del fuego del pogrom que te tocaba?/ ¿a los 5 años?/ ¿tu madre sacando de la casa en llamas a varios hermanitos?/ ¿y muerta a tu hermanita?/ ¿con todo eso/ por todo eso/ contra/ me querés?/ ¿me pedías que fuera tu hermanita?» (Gelman 2012: 789).

13 La experiencia del exilio y de la dictadura, de la muerte de sus compañeros de militancia y la desaparición de su hijo, constituido en el asunto central de su poesía de madurez, acerca a Gelman a la trágica trayectoria de sus padres y de los millones de judíos perseguidos y exterminados en Europa. El gran escritor al que hermanarse mediante el judaísmo, como Kafka en Pizarnik, es, en Gelman, Paul Celan. Un poema de Valer la pena ( ciudad de México, 1996-2000 »), titulado « País », incluye este verso: « Tumbas cavadas en el agua, Paul Celan ». La referencia evidente es el poema más célebre de Celan, "Todesfuge »: " wie schaufeln ein Grab in den Lüfren...» (" cavamos una fosa en el aire...»). La alusión implícita, aquí, a los hornos crematorios, se vuelve, en Gelman, hacia los cuerpos arrojados al Río de la Plata -y, probablemente, también, al suicidio de Celan arrojándose al Sena. El aire es reemplazado por el agua: en ambos casos, la idea de " cavar» significa la imposibilidad de la tumba, que solo existe en la tierra, y que es obligatoria según la ley judía; al asesinato sigue el ulterior ultraje, la desaparición del cuerpo, que hurta a los deudos el rito del funeral. Aquí, el poema se vuelve el único lugar donde es posible cavar la tumba. A la vez, la superposición del « aire » de las chimeneas de los campos de exterminio nazi con el «agua " del Río de la Plata da al terrorismo de Estado impuesto por la dictadura argentina la categoría de nuevo holocausto. Celan será, para Gelman, el emblema del poeta contemporáneo, el que debe enfrentarse a una nueva forma de lo inefable -de lo necesariamente hermético, puesto que su significado no puede darse abiertamente sino a través de un acto de descriframiento o re-ciframiento- y a la obligación de dar cuenta de aquello para lo que toda lengua es lengua muerta. Reaparece en « Vengan », del último libro de Gelman, El emperrado corazón amora (2011):

William Blake, Hölderlin, Celan, René

Char, $i$ a dónde

se han ido, compañeros? Todo

lo paga amor, la dicha y la

desdicha de la palabra, sus

favores que inquietan

y giran en la tarde más triste (2012: 1.123)

14 En un comentario del poema "Tübingen, Jäner » de Celan, Philippe Lacoue-Labarthe señala: « Un poema, como recuerda 'El meridiano', está siempre 'en ruta', 'en camino'. La vía que el poema pretende abrirse es la de su propia fuente » (Lacoue-Labarthe 2006: 28). 
Pero esa peregrinación no es un tema del poema sino que se cumple a través de la lengua misma, y en esto la búsqueda de Gelman sigue la estela de Celan.

La inesperada figura en la que convergen Pizarnik y Gelman es la del artista Marc Chagall, nacido en Bielorrusia como Moishé Segal y doble exiliado: del comunismo primero, instalándose en París en 1923; del nazismo más tarde, escapando a Estados Unidos. Entre los poemas póstumos de Pizarnik, publicados como Textos de sombra y últimos poemas, hay uno titulado «El ojo de la alegría (un cuadro de Chagall y Schubert) »:

... una muchacha lleva un candelabro de siete brazos y baila detrás de los tristes músicos que tañen violines rotos en torno a una mujer verde abrazada a un unicornio y a una mujer azul abrazada a un gallo (Gelman 2012: 423).

La écfrasis del cuadro de Chagall pone de manifiesto uno de los emblemas del judaísmo, el candelabro de siete brazos, junto a la imagen de los «violines rotos ", que simboliza la ruptura definitiva del mundo judío de Europa central y oriental. La música que ya no puede ejecutarse sino mediante un instrumento roto puede leerse, también, como la lengua que ya no significa nada o cuyo significado ya es indescifrable, la lengua muerta. Por su parte, Gelman le dedica a Chagall una de sus columnas en Página/12, el 12 de octubre de 2000, a raíz de los siete lienzos que el artista había pintado en Moscú en los años veinte, «Introducción al teatro judío », para el Teatro Judío de Cámara del Estado, concebidos como escenografía para obras de Scholem Aleijem, que el estalinismo ocultó en un almacén y reaparecieron después de décadas, tras la caída del régimen soviético. Gelman aprovecha la ocasión para hablar de Kafka, otro gran enamorado del teatro idish: «Las mejores obras de Chagall -observa Gelman- alcanzan un nivel de metáfora visual rara vez alcanzado por el arte moderno » (Gelman 2005: 119).

17 Chagall, artista que, sin ocultar ni renunciar a su judaísmo, hizo vitrales para la catedral de Metz o la iglesia de la Fraumünster de Zurich; el único de los grandes pintores del orbe soviético que, tras muchos años de exilio, recibió, en vida, un homenaje en Moscú: una gran exposición retrospectiva en la galería Tretyakov, en 1973. Esta figura que parece no aceptar ninguna ortodoxia ni rechazar ninguna de sus filiaciones posibles, resultó ser el punto de intersección de dos trayectorias tan distintas como las de Pizarnik y Gelman.

\section{BIBLIOGRAPHY}

Gelman, Juan. Miradas. México: ERA, 2005.

Gelman, Juan. Poesía reunida 1956-2010. Barcelona: Seix Barral, 2012.

Mallarmé Stéphane. Divagations, « Crise de vers », Bibliothèque-Charpentier, Eugène Fasquelle éditeur, 1897, p. 235-251, disponible en https://fr.wikisource.org/wiki/Divagations/

Crise_de_vers

Mosès, Stephan. L'ange de l'histoire; Rosenzweig, Benjamin, Scholem. Paris: Ed. du Seuil, 1992. 
Hoffmansthal, Hugo von. « Una carta » (1902) en Carta de lord Chandos y otros textos en prosa.

Barcelona: Alba, 2001.

Pizarnik, Alejandra. Poesía completa. Barcelona: Lumen, 2001.

Pizarnik, Alejandra. Diarios. Barcelona: Lumen, 2003.

Kamenszain, Tamara. La boca del testimonio. Lo que dice la poesía. Buenos Aires: Norma, 2007.

Tzara, Tristan (2004): Siete manifiestos DADA. Barcelona, Tusquets

Venti, Patricia. La escritura invisible. El discurso autobiográfico en Alejandra Pizarnik. Barcelona: Anthropos, 2008.

\section{NOTES}

1. Stéphane Mallarmé, Divagations, "Crise de vers ", Bibliothèque-Charpentier, Eugène Fasquelle éditeur, 1897, p. 235-251, disponible en https://fr.wikisource.org/wiki/Divagations/ Crise_de_vers

\section{ABSTRACTS}

Engaging with Stephan Mosès' concept of « rebellion of the children », this article looks into the relation with judaism of two Argentinian poets born in the decade of 1930, Alejandra Pizarnik and Juan Gelman. Althought practicing very different, even opposed aesthetics, judaism appears in both in the later phase of their work. In Pizarnik, the Jewish question is linked to the figure of the father; in Gelman, to that of the mother. The treatment of language and of literary tradition reveal, in both poets, some keys that will here be brought to attention.

Tomando el concepto de « rebelión de los hijos » de Stephan Mosès, el presente artículo indaga en la relación con el judaísmo de dos poetas argentinos nacidos en la década de 1930, Alejandra Pizarnik y Juan Gelman. Aunque practicaron estéticas muy distintas, incluso opuestas, en ambos el judaísmo aparece tardíamente en su obra. En Pizarnik, la cuestión judía se vincula a la figura del padre; en Gelman, a la de la madre. El tratamiento del lenguaje y de la tradición literaria esconde, en ambos poetas, algunas claves que se intentan poner aquí de relieve.

En partant du concept de « rébellion des fils » de Stephen Mosès, cet article examine la relation que deux poètes argentins nés durant la décennie 1930, Alejandra Pizarnik et Juan Gelman, entretiennent avec le judaïsme. Bien qu'ils aient pratiqué des modalités esthétiques très différentes, voire opposées, dans les deux cas, le judaïsme apparaît tardivement dans leurs œuvres. Chez Pizarnik, la question juive a trait à la figure du père ; chez Gelman, à la figure de la mère. Le traitement opéré sur le langage et sur la tradition littéraire cache, dans tout les deux, quelques clés de lecture que cet article s'emploie à mettre en valeur. 
INDEX

Mots-clés: judaïsme, Kafka, idish, avant-garde, « non-alliance ».

Palabras claves: judaísmo, Kafka, idish, vanguardia, « no-alianza ».

Keywords: judaism, Kafka, idish, vanguard, « non-alliance ».

\section{AUTHOR}

\section{EDGARDO DOBRY}

Universidad de Barcelona

edobry@ub.edu 